\title{
Narrativas nacionales y pensamiento histórico en los libros de texto de Educación Secundaria de España y Francia. Análisis a partir del tratamiento de los contenidos de la Edad Moderna ${ }^{1}$
}

\author{
National Narratives and Historical Thinking in Secondary \\ Education Textbooks in Spain and France. An Analysis Based \\ on Contents Related to the Early Modern Period
}

\author{
Cosme J. Gómez Carrasco \\ Sebastián Molina Puche \\ Universidad de Murcia \\ cjgomez@um.es \\ smolina@um.es
}

Fecha de recepción: 26-2-2016

Fecha de aceptación: 19-1-2017

\section{RESUMEN}

El objetivo principal de este trabajo es indagar en las narrativas históricas y en las competencias desarrolladas en los libros de texto de Historia en Educación Secundaria, comparando los contenidos y el pensamiento histórico propuesto por los manuales escolares franceses y españoles sobre la Edad Moderna. Se ha realizado un estudio exploratorio con un tema transversal: las unidades didácticas de la Edad Moderna en $2^{\circ}$ de ESO en España y $4^{\circ}$ de Collège en Francia. Este estudio ha analizado de una forma comparativa tanto los contenidos sustantivos que presentan los manuales (qué conocimientos históricos se proponen en estos materiales educativos), como los contenidos estratégicos (cómo se presentan esos conocimientos y qué tipo de habilidades cognitivas se le exige al alumnado). Los datos muestran resultados dispares. Por un lado la nación (su origen y consolidación) sigue siendo el principal sujeto histórico en los manuales. Pero existe una gran diferencia en las competencias históricas propuestas al alumnado en España (con un aprendizaje más memorístico) y en Francia (con un análisis más profundo de las fuentes históricas).

1 Este artículo es resultado de los proyectos de investigación "La evaluación de las competencias y el desarrollo de capacidades cognitivas sobre historia en Educación Secundaria Obligatoria" (EDU2015-65621C3-2-R); "Red de investigación en enseñanza de las ciencias sociales" (EDU2014-51720-REDT RED 14) y "Familia, desigualdad social y cambio generacional en la España centro-meridional, siglos XVI-XIX" (HAR201348901-C6-6-R) financiados por el Ministerio de Economía y Competitividad. 
PALABRAS CLAVE: enseñanza de la historia, narrativa nacional, libros de texto, pensamiento histórico, competencias educativas.

\section{ABSTRACT}

The main objective of this paper is to look into the historical narratives and the competencies developed in secondary education history textbooks by comparing the contents and historical thinking on the Early Modern period proposed by French and Spanish textbooks. We carried out an exploratory study with a cross-cutting topic: the teaching units on the Early Modern period in the $2^{\text {nd }}$ year of ESO in Spain and $4^{\text {th }}$ year of Collège in France. This study comparatively analyses both the substantive contents presented in textbooks (the historical knowledge presented in these educational materials), and the strategic contents (the way this knowledge is presented, and the kind of cognitive skills required by students). The data shows mixed results. On the one hand the concept of nation (its origin and consolidation) remains the main historical subject in textbooks. But there is a major difference in terms of the historical skills proposed for students in Spain (rote learning) and France (a deeper analysis of historical sources).

KEY WORDS: history education, national narrative, textbooks, historical thinking, educational skills.

\section{INTRODUCCIÓN}

La historia, como ciencia, no es (no debe ser) una disciplina sólo para eruditos ni tampoco un saber estático: se trata de un campo de conocimiento en permanente construcción. De hecho, la historia científica ha ido confluyendo a lo largo del siglo XX con otras ciencias sociales (antropología, sociología, economía, derecho...) para incorporar los diversos planos que componen la realidad social como objeto de estudio. Esta forma de hacer historia, que bebe sobre todo de las influencias de la Escuela de Annales y de la corriente marxista de mediados del siglo XX (Braudel, 1968; Vilar, 1974), ha supuesto, en cierto modo, un cambio en la función social de la disciplina: la historia deja de tener como único objetivo exponer los grandes hechos y procesos que han servido para conformar los Estados-nación (Pérez Garzón, 2008), para convertirse en una disciplina cuya finalidad ha de ser mostrar a la ciudadanía distintas visiones del pasado que le lleven, por un lado, a comprender mejor el complejo y multicultural mundo en el que vivimos, y por otro, potenciar su espíritu crítico. Es cierto que, en sentido estricto, este cambio de funcionalidad ni se ha debido exclusivamente a la influencia de las citadas escuelas historiográficas (ha habido otras causas que han llevado a ello, tanto a nivel interno de la ciencia histórica como de carácter externo), ni se ha logrado de forma definitiva: el positivismo todavía mantiene cierta raigambre en la producción historiográfica y con este, la creación de relatos históricos de corte teleológico y determinista orientados a promover la identificación acrítica de la población hacia una determinada nación (López Facal, 2010).

Con todo, si en algún ámbito se ha podido observar más claramente esa dicotomía o doble vertiente de la funcionalidad de la historia no ha sido tanto en la producción historiográfica, como en el campo de la enseñanza de la misma.

En efecto, en este campo, en el que como indica Prats (2010) la disciplina histórica ha sido uno de los elementos que más han contribuido a conformar la visión sobre la identidad social y política de las naciones, desde hace unas décadas se está planteando qué 
historia se debe enseñar $y$, de igual modo, qué funcionalidad ha de tener la enseñanza de la disciplina. En este sentido, Carretero (2006) ha señalado la contraposición existente entre un enfoque en la enseñanza de la historia basado en un discurso identitario propio del Romanticismo o un relato crítico heredado de la llustración. En lo referido al primero de los enfoques, se trata de una historia muy relacionada con el surgimiento de los Estadosnación (Hobsbawm, 1997; Pérez, 2008; VanSledright, 2011). Es interesante el análisis que Carretero y otros (2013) realizan sobre los objetivos románticos de la enseñanza de la historia, y cómo estos no se alejan de la función específicamente identitaria. Según estos autores la influencia del Romanticismo en la enseñanza de la historia se manifiesta a través de tres cuestiones centrales: una valoración positiva del pasado y presente del propio grupo social, tanto en el ámbito local como nacional; la valoración positiva de la historia política del país y la identificación con los acontecimientos del pasado, personajes y héroes nacionales. Se trata de una enseñanza de la historia limitada (o ampliamente sesgada) por los hechos políticos y militares, y que tiene como finalidad la memorización de hechos, datos o fechas que configuran fundamentalmente las narrativas maestras de la nación (López Facal, 2010). Ese proceso que une memoria, historia e identidades se ha usado habitualmente por el poder a través del arte, la literatura, el cine o los medios de comunicación, para trasladar su mensaje y convertirlo en verdad socialmente aceptada (Rosa, 2004). Los libros de texto han ejercido un papel clave en este proceso (Alridge, 2006).

Frente a este tipo de enseñanza de la historia, se erige el otro gran enfoque que el citado Carretero (2006) enlaza con la llustración y la conformación de la historia como disciplina científica. En este se defiende que la principal funcionalidad de la historia, como materia educativa, es la de formar a ciudadanos críticos, participativos e interesados por el mundo en el que viven (Barton y Levstik, 2004). Es una funcionalidad de la enseñanza de la historia que conecta perfectamente con las últimas propuestas pedagógicas en Europa (Perrenoud, 2004) y, en el caso de España, con las más recientes reformas educativas (la Ley Orgánica de Educación, LOE, de 2006 y la Ley Orgánica para la Mejora de la Calidad Educativa, LOMCE, de 2013), que han introducido el concepto de competencias como un elemento transversal en los currícula. El concepto de competencias supone un nuevo reto para una enseñanza que desarrolle habilidades y capacidades de pensamiento más complejas. En opinión de López Facal (2013), las ciencias sociales en general y la historia en particular son disciplinas que hacen posible el desarrollo y aprendizaje de estas competencias educativas si sabemos interpretar correctamente este concepto. Ser competente implica saber interpretar el medio en el que el alumno interactúa, saber proponer alternativas y ser capaz de argumentar. Estas operaciones necesitan de un conocimiento sólido sobre cómo es y cómo funciona la sociedad, cómo se han ido generando y modificando las relaciones humanas a lo largo del tiempo, qué consecuencias han tenido y tienen las acciones que realizan las personas y los colectivos (López Facal, 2013). La adaptación de las competencias educativas a la materia de historia implica una alfabetización histórica del alumnado que sobrepase la memorización de conceptos, datos y fechas del pasado y que sepa interpretar adecuadamente las narrativas históricas predominantes en los currícula y los libros de texto. Es decir, un modelo cognitivo de aprendizaje diferente, donde se enseñe a pensar históricamente (Gómez, Ortuño y Molina, 2014).

No cabe duda que se trata, grosso modo, de la contraposición de dos visiones de la enseñanza de la historia y de su función social, casi antagónicas, o al menos de muy difícil complementación. Entre otras razones porque mientras que la primera forma de enseñar historia fomenta, sobre todo, la creación de identidades colectivas excluyentes al tener como eje discursivo el relato nacional, cuando no étnico o cultural, basado en subrayar las diferencias existentes entre el "nosotros" y "los otros", en el segundo caso esa potenciación 
del espíritu crítico ha de ayudar a la construcción de identidades múltiples o inclusivas (las fidelidades concéntricas a las que se refiere López Facal, 2006), en la que se muestren las características que tienen los distintos colectivos que componen una sociedad para dar a conocer los rasgos o elementos compartidos (Molina Puche, 2015).

Obsta decir que, en un mundo cada vez más globalizado, en el que las sociedades están muy alejadas de esa uniformidad étnica, cultural, lingüística y religiosa que propugnaban los Estados-nación decimonónicos, la que podríamos denominar como "visión tradicional" de la enseñanza de la historia debiera tener cada vez menor cabida en las aulas. Sin embargo, los estudios realizados en las últimas décadas para intentar determinar qué historia y con qué finalidad se está enseñando a los alumnos tanto en España (Gómez y Miralles, 2013 y 2015; López Facal, 2010; Merchán, 2009) como en otros países occidentales (Barca, 2000; Barton, 2010; Heimberg, 2005), han demostrado que la realidad es bien distinta: la historia se sigue instrumentalizando para "crear nación".

Evidentemente, parece ser un contrasentido, una paradoja. Pero la cuestión es ¿cuál puede ser la causa? Aunque alguno de los estudios realizados considera que el problema puede estar en la formación inicial del profesorado, que en casos como el español se encuentra muy centrada en la disciplina histórica y muy poco en la parte más didáctica o pedagógica, lo que lleva a que muchos de los nuevos profesores acaben reproduciendo los métodos y modos de enseñanza de sus propios "maestros" (Molina Puche y otros, 2016), buena parte de los estudios incide en que el principal problema se encuentra en los currícula (Heimberg, 2011; Pérez Garzón, 2008; Rodríguez Lestegás, 2008) y en la principal herramienta con la que cuentan los docentes: los manuales escolares (López Facal, 2010; Nichols, 2006; Thornton, 2006; Valls, 2008).

En efecto, hay una coincidencia entre los investigadores al caracterizar al libro de texto como un elemento clave para analizar la forma en la que el alumnado concibe el conocimiento histórico (Foster, 2012). Igualmente hay unanimidad en vincular la calidad de los libros de texto en la materia de historia a las posibilidades de ser usados para fomentar las competencias históricas y las habilidades cognitivas en el alumnado (Sáiz, 2013). En España los trabajos sobre los libros de texto constituyen una línea de investigación muy fructífera en los últimos veinte años (Gómez, Miralles y Cózar, 2014; Sáiz, 2013; Valls 2001 y 2008). En Europa el análisis de libros de texto es una línea de investigación fundamental para comprender las tensiones en la enseñanza de la historia, sus relaciones con el poder, la construcción de identidades colectivas, los currícula y el contexto histórico, social y cultural. Los trabajos de Audigier y Tutiaux-Guillon (2004), Cajani (2006), Elmersjö (2014), Nygren (2011), Nicholls (2003), Pingel (2000) y Stöber (2013) han profundizado sobre estas temáticas, donde priman el análisis de la construcción del concepto de Europa y la presencia de los grandes traumas sociales y políticos. Una trayectoria parecida sobre esta línea de investigación se ha desarrollado en Estados Unidos, como muestran los trabajos de Foster (1999) y Moreau (2003). En este caso las investigaciones han puesto énfasis en la construcción de la nación, el tratamiento de las principales figuras políticas del país y en los valores sociales que se transmiten en los libros de texto de historia. De igual forma, en Latinoamérica las investigaciones sobre los manuales escolares de historia han incidido en el mensaje identitario que transmiten a través de temas clave como los procesos de independencia o la llegada de Colón a América (Carretero, Rosa y González, 2006). La mayor parte de estos estudios ha puesto el acento en el discurso lineal, principalmente nacional, de los manuales de historia y su función como transmisores del saber y del sentido de la realidad hegemónica por parte de las autoridades o del poder, que generalmente no se cuestiona en sus páginas (Carretero, 2006). De hecho, en palabras de Barton (2010), los manuales de historia expresan el pasado nacional que enfatiza el papel de los padres 
fundadores o documentos nacionales de referencia, acompañados a veces por guerras, batallas y otros acontecimientos bélicos.

A pesar del interés que suscitan estas temáticas ligadas a la construcción de identidades colectivas, en la actualidad hay un consenso en la comunidad científica sobre la necesidad de ampliar las líneas de investigación sobre los manuales a su contexto de uso en las aulas (Foster y Crawford, 2006; Valls, 2001). El reto de las investigaciones actuales pasa por el análisis y adaptación de esas competencias educativas propuestas por los currícula a la disciplina histórica, a través de actividades formativas que desarrollen tanto contenidos conceptuales como el pensamiento histórico. Es un enfoque que comienza a replantear esta adaptación como competencias históricas y que incide en las habilidades del historiador, la búsqueda, selección y tratamiento de fuentes históricas, en el análisis de causas y consecuencias, el cambio y la continuidad en los procesos históricos, la empatía o la perspectiva histórica (Barton, 2008; Gómez y Miralles, 2015; Gómez, Ortuño y Molina, 2014; Domínguez, 2015; Lee, 2005; López-Facal, 2014; Sáiz, 2013; Seixas y Morton, 2013; VanSledright, 2014; Wineburg, 2001). En una de sus últimas monografías, Seixas y Morton (2013) incidieron en seis conceptos clave para el desarrollo del pensamiento histórico: relevancia histórica, fuentes, cambio y continuidad, causas y consecuencias, perspectiva histórica y la dimensión ética de la historia. El papel clave que juega el libro de texto en el desarrollo de la clase de historia en Educación Secundaria obliga a realizar un análisis en profundidad de los contenidos, las actividades formativas y su adecuación a una correcta alfabetización histórica del alumnado.

Con la finalidad de conocer la presencia de narrativas nacionales en los manuales, así como la aplicación de esas competencias en los libros de texto de historia, el presente estudio analiza de forma comparativa (España-Francia) tanto los contenidos sustantivos que presentan los manuales (qué conocimientos históricos se proponen en estos materiales educativos), como los contenidos estratégicos (cómo se presentan esos conocimientos, y qué tipo de habilidades cognitivas se le exige al alumnado). Hemos optado por realizar un análisis comparativo entre dos realidades distintas (esto es, dos marcos curriculares diferentes) para intentar calibrar, de esta manera, hasta qué punto son los currícula o las editoriales quienes inciden en el enfoque que se sigue en la enseñanza de la historia. Para conseguir esta finalidad se ha realizado un estudio exploratorio de las actividades propuestas al alumnado de una época trascendental en la comprensión del actual sistema social, económico, político, cultural y de pensamiento: la Edad Moderna. Todos los procesos históricos que se desarrollaron en este período fueron el germen de lo que algunos autores han denominado como "modernidad" (Le Goff, 1988) y se presenta por lo tanto como clave en la comprensión de la organización social, política, económica y cultural actual.

\section{METODOLOGÍA}

\subsection{Objetivos}

El objetivo principal de este trabajo es indagar en las narrativas históricas y en las competencias desarrolladas en los libros de texto de historia en Educación Secundaria, comparando los contenidos y las habilidades cognitivas propuestas por los manuales escolares franceses y españoles sobre la Edad Moderna. Se ha realizado un estudio exploratorio con un tema transversal: las unidades didácticas de la Edad Moderna en $2^{\circ}$ de ESO en España y $4^{\circ}$ de Collège en Francia. Para ello se han formulado cuatro objetivos específicos:

1. Comparar los contenidos históricos y las narrativas propuestas sobre la Edad Moderna en el currículo escolar de Educación Secundaria en España y Francia. 
2. Diferenciar la tipología de contenidos sobre la Edad Moderna (historia política, historia social, historia económica, historia del arte y cultural) que están presentes en las actividades de los libros de historia de Educación Secundaria en España y Francia.

3. Clasificar la tipología de actividades propuestas por los libros de texto de historia en las unidades didácticas sobre la Edad Moderna en Educación Secundaria en España y Francia.

4. Contrastar el nivel cognitivo y las competencias históricas que se desarrollan en las actividades propuestas por los libros de texto de historia en Educación Secundaria en España y Francia.

\subsection{Fuentes, métodos y categorización de datos}

Los libros de texto son una trascendental fuente de información para el análisis del discurso histórico oficialista y su transmisión a la sociedad. En este sentido cobra importancia el concepto utilizado por Wertsch (2002) de plantilla narrativa esquemática (schematic narrative template) como herramienta cultural de mediación generada y distribuida entre un grupo social aplicable a las narrativas nacionales (Carretero y López, 2010; Carretero, López, González y Rodríguez-Moneo, 2012). Existe una poderosa mediación narrativa en los conocimientos y recuerdos históricos de estudiantes y profesores por el propio peso de las narrativas nacionales en el currículo y en los libros de texto. De hecho, las investigaciones sobre los usos públicos de la historia y la función de la enseñanza de la historia vienen señalando la estrecha relación que esta tiene con el nacionalismo y la construcción de identidades nacionales. Esta realidad también se ha constatado para la educación histórica en España (Álvarez Junco, 2013; López Facal, 2009). Hay que tener en cuenta que la mayoría del alumnado ha aprendido los principales contenidos históricos a través del relato de estas narrativas maestras presentes en los libros de texto (Foster, 2012). Por esta cuestión la revisión y análisis de estas narrativas permite lo que Chartier (2007: 22) definió como "la brecha existente entre el pasado y su representación, entre lo que fue y no es más y las construcciones narrativas que se proponen ocupar el lugar de ese pasado".

Para analizar los contenidos históricos y las narrativas presentes en Educación Secundaria se ha recogido información de los currícula escolares a través de un análisis cualitativo de contenidos.

Para analizar las tipologías de contenidos y actividades y las competencias históricas se ha realizado un estudio cuantitativo de las actividades propuestas por los libros de texto de $2^{\circ}$ de la ESO (España) y $4^{\circ}$ de Collège (Francia). La elección de estos dos cursos para el análisis de las competencias históricas se debe fundamentalmente a la coincidencia en la edad del alumnado (13-14 años). El total de la muestra para el análisis cuantitativo la componen 1443 actividades (531 en los libros de España y 912 en los libros de texto franceses). Las editoriales escogidas han sido Anaya (2010), Oxford (2008) y Vicens Vives (2012) en España para $2^{\circ}$ de la ESO, y Bordas (2011), Belin (2011) y Lelivrescolaire (2011) en Francia para $4^{\circ}$ de Collège. El muestreo tuvo un carácter incidental, aunque se escogieron seis editoriales con gran representación y de uso común en los centros de Educación Secundaria de ambos países.

Como veremos a continuación, los datos obtenidos se han agrupado por países. Somos conscientes de que, entre las distintas editoriales, y sobre todo en el caso español, las diferencias pueden llegar a ser importantes en aspectos puntuales, como ya hemos 
demostrado en estudios anteriores (Gómez, 2014; Gómez, Molina y Pagán, 2012). En el caso de los libros de texto españoles hay diferencias tanto en los contenidos propuestos como en la tipología de actividades que debe realizar el alumnado. En cuanto a los contenidos, el manual más parco es el de Oxford, pues sólo le dedica dos temas. En el otro extremo está Vicens Vives, con una gran profundidad tanto en los temas sobre el descubrimiento y colonización de América, como en temas sociales y económicos. Anaya también incide en más temas sociales y económicos (referentes a la casa, vida cotidiana y vestido) que la editorial Oxford, aunque con un número menor de páginas que la editorial Vicens Vives. En cuanto a la tipología de actividades, quien más apuesta por preguntas cortas y por una menor exigencia cognitiva es la editorial Oxford. En el otro extremo está Anaya, con un número mayor de actividades de nivel cognitivo 2 y con un notable número de preguntas sobre imágenes y figuras. Vicens Vives también presenta un buen número de actividades sobre imágenes y con una mayor exigencia cognitiva, pero el porcentaje sobre el total de ejercicios es menor que Anaya.

En el caso francés hay una mayor homogeneidad en contenidos y en la tipología de actividades. Tanto los conocimientos expuestos sobre la Edad Moderna como el número de páginas son muy similares. Las tres editoriales siguen los preceptos curriculares de manera casi literal. Las diferencias suelen estar en matices. Por ejemplo, en la editorial Lelivrescolaire optan por utilizar un estudio de caso sobre Londres para explicar las ciudades marítimas del siglo XVIII, mientras que Bordas utiliza Nantes para explicar el mismo contenido. Además Lelivrescolaire opta por un capítulo específico sobre historia del arte, mientras que Belin y Bordas tratan este tema de forma sintética al final de cada capítulo. En Bordas además utilizan muchas imágenes, muy amplias y con una gran calidad gráfica. Belin sigue un patrón muy similar a Bordas en su apartado gráfico, mientras que Lelivrescolaire tiene un tono más sobrio en imágenes y opta por utilizar en las actividades un mayor número de textos de historiadores y de la propia época estudiada.

En todo caso, el hecho de que, en términos generales, hayamos aunado los resultados por países y no por editoriales responde a una razón sencilla: las diferencias, que son más acusadas en el caso español, no son tan grandes como para marcarlas una a una, pues en ese caso el texto que presentamos acabaría siendo de una densidad difícilmente comprensible.

En cuanto al instrumento de recogida de información de las actividades de los libros de texto, se ha diseñado en una base de datos en ACCESS. Se elaboraron tres parrillas de registro para después codificar los datos resultantes en tablas relacionales. Las 1443 actividades recogidas de los manuales se han sistematizado en torno a tres categorías: contenidos históricos, tipología de actividad y nivel cognitivo que exigen al alumnado (Gómez, 2014; Gómez y Miralles, 2016; y Sáiz, 2013).

\section{ANÁLISIS DE RESULTADOS}

\subsection{Europa y la construcción de la nación como sujeto histórico}

En respuesta al primero de los objetivos, se han analizado los contenidos correspondientes a la Ley Orgánica de Educación en España(LOE, 2006, más concretamente su adaptación para la Comunidad Autónoma de la Región de Murcia: decreto 291/2007 de la CARM) y el Programa Académico de 2008 en Francia, ya que son sobre los que se basan los libros de texto utilizados. Los cambios legislativos que se han producido entre 2013 y 2015 en España y Francia no han alterado en lo sustantivo los contenidos de la Edad Moderna propuestos en el currículo (en el caso español, los contenidos son prácticamente los mismos desde comienzos de los años noventa (Molina, Ortuño y Gómez, 2014). Tanto en España como en Francia los conocimientos sobre los siglos XVI y XVII se imparten en un 
curso diferente a los contenidos sobre el siglo XVIII. En el currículo español las principales temáticas sobre los siglos XVI y XVII giran en torno al descubrimiento y conquista de América; la conceptualización del poder y su representación en las monarquías europeas de estos siglos; hechos, batallas y figuras esenciales del Imperio Hispánico; y el arte y la cultura del Renacimiento y del Barroco. La sociedad y economía tienen un lugar más secundario. Con la LOE (2006) estos temas se impartían en $2^{\circ}$ de la ESO y se retomaban, de forma más sintética, en $4^{\circ}$ curso. Con la nueva ley educativa (LOMCE, 2013) pueden impartirse en $3^{\circ}$ de la ESO (como ocurre en el Decreto de la Región de Murcia). El siglo XVIII tiene un peso pequeño en el currículo español, con uno o dos temas a comienzo de $4^{\circ}$ de la ESO, casi como un prólogo de la Edad Contemporánea. Las principales temáticas son la guerra de Sucesión, el reformismo borbónico y la llustración, tanto en europea como en España (ver anexo 4).

En el caso francés, para los siglos XVI y XVII el currículo le otorga un importante peso a los temas culturales (Renacimiento, Humanismo, la nueva visión del mundo...) y temas ligados a la construcción y representación del poder absoluto basados en Luis XIV y en el palacio de Versalles. Estos temas se imparten en $5^{\circ}$ de Collège (alumnado de 12-13 años). El siglo XVIII se imparte en $4^{\circ}$ de Collège (13-14 años), con una mayor profundidad que en el caso español y a través de temas transversales (al menos cinco temas): Europa y el mundo a principios del siglo XVIII; la Europa de las Luces, la esclavitud y la trata de esclavos; las dificultades de la monarquía de Luis XVI; y la Revolución francesa (ver anexo 5).

Los datos analizados muestran que el conocimiento histórico transmitido al alumnado sigue bajo el predominio de un relato unidimensional de corte político y tradicional, mucho más acusado en el caso de España, y más matizado en el caso francés. El discurso histórico hegemónico favorece una visión positivista de la historia, centrada en la idea de tiempo lineal y el progreso continuo de la civilización, fijando los contenidos en la memorización de reyes, ministros, prohombres, estadistas, fechas de batallas, guerras o tratados de paz, mezclado con temas culturales y artísticos (Gómez, 2014). Hay algunas diferencias entre el caso francés y español. Mientras que en el currículo español se combina un tratamiento de los contenidos que mezcla el positivismo clásico (basado en la cronología y la enumeración de hechos y datos) con un planteamiento estructural (dividiendo entre historia política, historia social, historia del arte...), en el caso francés se plantean temas transversales muy cercanos al enfoque cultural y de las mentalidades de la última generación de Annales. Por ello hay algunas temáticas muy interesantes y con un espacio de tratamiento amplio en el caso francés como el esclavismo y la trata de negros, la Europa de las Luces, el desarrollo de la intimidad en el siglo XVIII, el nacimiento del artista, etcétera.

En respuesta al segundo objetivo, el análisis de los contenidos históricos predominantes en las actividades de los manuales muestra la hegemonía de la historia política e institucional, la historia del arte e historia cultural. Estas temáticas suponen el $82 \%$ de las actividades de los manuales españoles y el $75 \%$ de los manuales franceses (tabla 1). En el caso español dominan preguntas sobre los conceptos del poder, la monarquía y la formación del Estado en la Edad Moderna; la trayectoria de la Monarquía Hispánica; características de estilos artísticos del Renacimiento y Barroco. Dominan preguntas como "Define los siguientes términos: Humanismo, monarquía autoritaria, reforma protestante...", “¿Qué se reconoció en la Paz de Westfalia?". Preguntas de historia social y económica como "Escribe las causas del descenso de la población producido en Europa y en España", "Compara la sociedad del siglo XVI con la sociedad medieval. Indica semejanzas y diferencias" son escasas y sólo aparecen en una de cada seis actividades. En el caso francés hay un mayor porcentaje de actividades dedicadas a la historia social y económica, ya que existe un tema dedicado a Europa y el Mundo a comienzos del siglo XVIII, donde se incide en el comercio internacional 
y las ciudades marítimas, así como un tema dedicado exclusivamente al esclavismo, donde hay un mayor tratamiento de temas sociales y económicos, con preguntas como "¿En qué continente se efectúa la venta de esclavos? ¿Cómo se desarrollaba?"; "Describid los productos transportados por la Compañía de Indias. ¿De dónde venían? ¿A quién estaban destinados?"

Tabla 1. Conocimientos históricos propuestos en las actividades de los libros de texto de $2^{\circ}$ de la ESO de España y $4^{\circ}$ de Collège.

\begin{tabular}{|c|c|c|}
\hline $\begin{array}{c}\text { Conocimientos } \\
\text { históricos }\end{array}$ & Manuales España & Manuales Francia \\
\hline $\begin{array}{c}\text { Historia del arte y } \\
\text { cultural }\end{array}$ & $36^{\prime} 9 \%$ & $35^{\prime} 2 \%$ \\
\hline $\begin{array}{c}\text { Historia política e } \\
\text { institucional }\end{array}$ & $45^{\prime} 6 \%$ & $40 \%$ \\
\hline $\begin{array}{c}\text { Historia social y } \\
\text { económica }\end{array}$ & $17^{\prime} 5 \%$ & $24{ }^{\prime} \%$ \\
\hline TOTAL & $100 \%$ & $100 \%$ \\
\hline
\end{tabular}

A pesar de que en el caso francés hay más presencia de contenidos asociados a otras realidades europeas a través de estudios de caso concretos (como la ciudad de Londres para hablar de las ciudades marítimas), tanto en Francia como en España se sigue un discurso lineal que tiene como sujeto histórico a la nación, su origen, construcción y consolidación (Carretero y Van Alphen, 2014) pero en un marco europeo. Así, para abordar cualquier época histórica los libros de texto españoles y franceses proponen una estructura común: política, población, sociedad, economía, cultura y arte. Estos contenidos suelen enmarcarse en unas líneas de larga duración (grandes épocas históricas: Edad Media, Edad Moderna, etcétera); en unas coyunturas basadas en un "tiempo medio" (períodos y coyunturas políticas y económicas de crecimiento y recesión o períodos culturales: Renacimiento, Barroco, etcétera); y en un "tiempo corto" basado principalmente en la trayectoria de las instituciones de poder (acontecimientos políticos, batallas, guerras, etcétera). El hecho de utilizar estas tres dimensiones temporales obliga a buscar una entidad supranacional en la que enmarcar esos procesos de larga duración. Cuando los manuales españoles y franceses explican sus coyunturas políticas, económicas o culturales, lo hacen en el contexto de procesos de larga duración europeos. Así, antes de adentrarse en temas nacionales, los libros de texto abordan temáticas como el feudalismo en Europa, la reafirmación del poder de las monarquías medievales frente a poder señorial, la construcción de las monarquías autoritarias, el absolutismo, el Humanismo en Europa, o la revolución científica y sus consecuencias culturales y científicas. Estos temas son coincidentes en los manuales franceses y españoles, mostrando el devenir histórico nacional en un marco de construcción europea. La diferencia está en el enfoque de esas temáticas, con un mayor peso de la indagación y la reflexión en los libros de texto franceses. 


\subsection{Unas competencias históricas desequilibradas}

Una correcta alfabetización histórica del alumnado debe presentar los contenidos a través de actividades formativas que movilicen capacidades cognitivas complejas y habilidades de pensamiento relacionadas con la disciplina. En respuesta al tercer objetivo del trabajo, los datos muestran resultados muy dispares en los libros de texto de España y Francia (tabla 2). En realidad estos resultados responden a la propia estructura del manual. Los manuales españoles presentan las unidades didácticas con un amplio texto elaborado por los autores del libro, actividades sobre ese texto, e imágenes principalmente estéticas y de decoración (Gómez y Miralles, 2016). Sólo el 31 \% de las imágenes tiene asociadas actividades y la poca presencia de fuentes primarias y textos de historiadores es llamativa (Gómez, Molina y Pagán, 2012). Por el contrario, en Francia el texto elaborado por los autores es mucho más reducido y la mayor parte de las páginas está dedicada a textos de la época, fragmentos de historiadores e imágenes sobre las que se elabora una gran cantidad de actividades. Por ello en España dominan las preguntas cortas sobre los epígrafes del manual (60\% de las actividades), mientras que las cuestiones sobre fuentes primarias, figuras e imágenes se reduce al $25 \%$. En los libros de texto franceses, por el contrario, las actividades sobre textos, figuras e imágenes suponen casi el $80 \%$ de las actividades y las preguntas cortas sobre epígrafes del manual se reducen al 7,6\%. No hay una sola imagen de los manuales franceses que no tenga actividades asociadas a ella. En cambio, en los manuales españoles siete de cada diez imágenes no tienen actividades asociadas.

Tabla 2. Tipología de actividades en los libros de texto de $2^{\circ}$ de la ESO de España y $4^{\circ}$ de Collège.

\begin{tabular}{|c|c|c|c|c|}
\hline TIPOLOGÍA ACTIVIDAD & $\begin{array}{c}\text { Frecuencia } \\
\text { España }\end{array}$ & $\begin{array}{c}\text { Porcentaje } \\
\text { España }\end{array}$ & $\begin{array}{c}\text { Frecuencia } \\
\text { Francia }\end{array}$ & $\begin{array}{c}\text { Porcentaje } \\
\text { Francia }\end{array}$ \\
\hline PREGUNTA CORTA & 319 & $60^{\prime} 1$ & 69 & $77^{\prime} 6$ \\
\hline FIGURAS/IMÁGENES & 110 & $20^{\prime} 7$ & 401 & $43^{\prime} 9$ \\
\hline PRUEBA OBJETIVA & 50 & $9^{\prime} 4$ & 18 & 2 \\
\hline COMENTARIO DE TEXTO & 27 & $5^{\prime} 1$ & 318 & $34^{\prime} 9$ \\
\hline BÚSQUEDA DE INFORMACIÓN & 18 & $3^{\prime} 4$ & 41 & $4{ }^{\prime} 5$ \\
\hline CREACIÓN & 4 & $0^{\prime} 8$ & 18 & 2 \\
\hline ENSAYO & 3 & $0^{\prime} 6$ & 47 & $5^{\prime} 1$ \\
\hline TOTAL & 531 & 100 & 912 & 100 \\
\hline
\end{tabular}

En consecuencia, y si se examina el nivel cognitivo exigido (tabla 3, objetivo cuatro de la investigación), se puede concluir que en los manuales españoles analizados se plantea un tratamiento superficial de los contenidos históricos en comparación con los manuales franceses. La mayoría de los ejercicios planteados por los libros de texto españoles son de "cortar y pegar", seleccionar parte de información anteriormente ofrecida para recordarla o reproducirla. La tipología de ejercicios más común son las preguntas cortas, que exigen un nivel cognitivo muy bajo y que se responden con un término, concepto o fecha, cuya 
solución está en el propio texto del libro, a escasos centímetros de la pregunta. La presencia de actividades más complejas y creativas que orienten al alumnado a formar su propio pensamiento de los procesos históricos son escasas. Las actividades sobre figuras e imágenes tampoco explotan su potencialidad didáctica y se limitan en gran parte a que el alumnado describa de forma sencilla los elementos representados. Los comentarios de texto sólo aparecen en el $5 \%$ de las actividades, en las que se exige al alumnado que parafrasee o localice algún fragmento textual. Así, sólo cuatro de cada diez actividades demandan del alumnado habilidades cognitivas de comprensión o aplicación de conocimientos históricos.

Tabla 3. Nivel cognitivo exigido en las actividades de los libros de texto de $2^{\circ}$ de la ESO de España y $4^{\circ}$ de Collège.

\begin{tabular}{|c|c|c|c|c|}
\hline $\begin{array}{c}\text { Nivel } \\
\text { cognitivo }\end{array}$ & $\begin{array}{c}\text { Frecuencia } \\
\text { España }\end{array}$ & $\begin{array}{c}\text { Porcentaje } \\
\text { España }\end{array}$ & $\begin{array}{c}\text { Frecuencia } \\
\text { Francia }\end{array}$ & $\begin{array}{c}\text { Porcentaje } \\
\text { Francia }\end{array}$ \\
\hline NIVEL 1 & 321 & $60^{\prime} 5$ & 194 & $21^{\prime} 3$ \\
\hline NIVEL 2 & 184 & $34^{\prime} 7$ & 573 & $62^{\prime} 8$ \\
\hline NIVEL 3 & 26 & $44^{\prime} 9$ & 145 & $15^{\prime} 9$ \\
\hline TOTAL & 531 & 100 & 912 & 100 \\
\hline
\end{tabular}

En los manuales franceses, por el contrario, se trabajan de una forma más profunda las imágenes y fuentes primarias. Las actividades tienen el objetivo de interrogar a la fuente desde muchas perspectivas, incluyendo preguntas que necesitan de varios recursos (textuales e icónicos). El objetivo principal de estas actividades es el fomento de la interpretación histórica por parte del alumnado, por ello ocho de cada diez actividades exigen habilidades de comprensión y aplicación de conocimientos, relacionar conceptos, preguntas inferenciales y ejercicios procedimentales. Sólo dos de cada diez actividades de los manuales franceses exigen un nivel cognitivo bajo y están más relacionadas con las preguntas cortas de los epígrafes y algunas actividades asociadas a imágenes y textos que sólo implican la localización y reproducción de información.

En el caso de los manuales españoles la presencia de los conceptos históricos de segundo orden establecidos por Seixas y Morton (2013) como causas y consecuencias o cambios y permanencias, están ligados generalmente a actividades de baja exigencia cognitiva. Tareas que permitirían una consolidación de estos conceptos en el alumnado como el planteamiento de problemas históricos relevantes, la redacción de informes a partir del análisis de documentos de diferente naturaleza (textos, imágenes, gráficos, mapas, etcétera), los estudios de caso, ejercicios de simulación, empatía y perspectiva histórica, o pequeñas investigaciones guiadas tienen muy reducido espacio, por no decir nulo, en las actividades de los manuales españoles. La insistencia en ejercicios de respuesta corta, de hechos o conceptos concretos, no sólo va generando en el alumnado una concepción histórica acrítica, sino también en cierto sentido atemporal, debido a la escasez de actividades que desarrollen las diferentes categorías del tiempo histórico (Gómez y Miralles, 2015).

La poca presencia de estas habilidades estratégicas a la hora de abordar el pasado supone un hándicap negativo en la formación histórica del alumnado. No hay que olvidar que conocemos el pasado a partir de fuentes y trazos de información, y que los conocimientos históricos provienen del análisis de diferentes tipos de fuentes de información a través de 
una metodología y de un contexto teórico propio de la disciplina (Gómez, Ortuño y Molina, 2014; VanSledright, 2014). El tratamiento e interpretación de fuentes está mejor desarrollado en los manuales franceses, pues ocho de cada diez actividades están basadas en textos o imágenes. Junto al desarrollo de habilidades en la interpretación de fuentes históricas, tanto el análisis de causas y consecuencias, como los cambios y las permanencias, también están mejor tratadas. A pesar de ello algunos conceptos de pensamiento histórico propuestos por Seixas y Morton (2013) son tratados de forma más superficial en ambos casos. Preguntas sobre relevancia histórica (que el alumnado se interrogue sobre por qué es considerado un hecho/acontecimiento como relevante), ejercicios de simulación o de perspectiva histórica, o trabajar con ejercicios de conciencia histórica (conectando fenómenos del pasado y del presente, etcétera) tienen un peso menor.

\section{DISCUSIÓN Y CONCLUSIONES}

La enseñanza de los contenidos históricos debe tener en cuenta la necesidad de desarrollar en el alumnado el planteamiento de problemas del pasado de forma crítica, el uso y manejo de fuentes y pruebas históricas, el desarrollo de una conciencia histórica, y una correcta argumentación, donde se vaya más allá de un relato lineal y acrítico del pasado y se tengan en cuenta las causas y consecuencias, los cambios, las continuidades (Gómez, Ortuño y Molina, 2014). Por lo cual la adaptación de las competencias educativas a la materia de historia implica una alfabetización histórica del alumnado que sobrepase la memorización de conceptos, datos y fechas del pasado. En este sentido, los resultados obtenidos en el análisis de los conocimientos sobre la Edad Moderna en el currículo francés y español y el análisis de los contenidos y competencias históricas en 1443 actividades de manuales (913 ejercicios de libros de texto franceses y 531 de libros de texto españoles) muestran resultados dispares. En general los manuales suelen presentar una visión lineal del pasado. Pero la disparidad de resultados está relacionada con las habilidades de pensamiento histórico propuestas por las actividades.

En respuesta a los dos primeros objetivos de la investigación, los resultados muestran una falta de actualización de contenidos disciplinares por parte de los libros de texto, si comparamos las temáticas con la producción historiográfica reciente recogida en Gómez (2014). En este análisis se muestra cómo las principales temáticas abordadas por la historiografía modernista son: fiscalidad, hacienda, oligarquías locales, organización del territorio, relaciones verticales y horizontales de poder entre las distintas instituciones, la familia, el matrimonio y la herencia, la vida cotidiana, la imagen del poder, las ceremonias y festividades o la conflictividad social. Son temáticas muy alejadas del discurso lineal, político y tradicional que se mantiene en los manuales. Esto nos lleva a cuestionar el nivel de transposición didáctica entre el saber investigado y el saber divulgado a través de la escolarización obligatoria (Sáiz, 2010). Aunque la actualización de contenido en los manuales supondría un avance positivo, la reducción de la problemática al nivel de actualización de contenidos conlleva una visión errónea de la transposición didáctica: el saber científico no se transforma directamente en saber enseñable, sino que el alumnado lo va adaptando a sus esquemas mentales y a su conocimiento cotidiano o vulgar de la historia, fuertemente influido por la cultura audiovisual (Sáiz, 2010).

La historia que se enseña y se aprende en la escuela es diferente al conocimiento histórico producido por la historiografía académica. El conocimiento histórico escolar tiene una forma particular de significar el pasado donde tiene una gran presencia el uso público del pasado dentro de la sociedad (Plá, 2013). Este conocimiento se da dentro de un centro escolar, lo que genera tanto elementos psicológicos y pedagógicos de aprendizaje que determinan las prácticas docentes, prescripciones curriculares que legitiman ciertas formas 
de pensar del pasado, controles burocráticos, historias de formación docente e historias de los alumnos que poseen sus propias percepciones de la historia y del pasado (Plá, 2013).

La aportación de los contenidos sustantivos a la alfabetización histórica del alumnado debe tener presente el concepto de relevancia histórica (Seixas y Morton, 2013). Se trata en este caso de presentar el significado del pasado y su conocimiento como una realidad no estática, sino en construcción continua a partir de interrogantes de investigación y que respondan a problemas actuales, o al menos a cuestiones significativas para el alumnado. Esto implica que hay que desarrollar la capacidad de interrogarse sobre qué y quién del pasado vale la pena ser recordado y estudiado y el por qué de su elección. La importancia o relevancia del pasado que se debe enseñar y aprender depende del enfoque o la perspectiva desde la que se muestre la disciplina histórica, la duración, el impacto social de ese proceso o acontecimiento histórico y su importancia particular en el contexto donde se enseña.

Lo importante con los alumnos de Educación Secundaria Obligatoria es presentar los contenidos históricos desde problemas sociales relevantes (Sáiz, 2010). Es decir, qué puede aportar el conocimiento de los procesos históricos surgidos en la Edad Moderna para comprender críticamente nuestra sociedad. Además de los elementos políticos omnipresentes en el libro de texto, existen muchas temáticas sociales y económicas de necesario análisis que generalmente obvian los manuales mayoritarios, o las dejan en segundo plano: la pobreza, las desigualdades sociales, los conflictos religiosos desde un punto de vista social (judeoconversos, moriscos, protestantes...), la diferenciación de roles en la familia por género y por edad, las solidaridades vecinales, la conflictividad y las formas de disciplinamiento social, la articulación del mercado interior, la organización territorial a través de lazos clientelares entre las oligarquías, etcétera. El menor peso de estas temáticas está relacionado con el importante papel que ocupa la nación como sujeto histórico en las narrativas históricas propuestas en los manuales.

En respuesta a los dos últimos objetivos de la investigación, los resultados muestran una gran disparidad en las competencias históricas propuestas por los libros de texto. En los manuales españoles la mayoría de ejercicios se basan principalmente en la repetición de conceptos, hechos y fechas concretas y, en menor medida, actividades de comprensión y aplicación de contenidos históricos. La reflexión es escasa, no existen actividades de empatía o perspectiva histórica de una forma compleja, apenas se les exige redacciones amplias ni ejercicios de ensayo que requieran de los alumnos habilidades narrativas sobre el pasado. Se muestra el conocimiento histórico como un saber cerrado, alejado de los intereses del alumnado, con un excesivo texto elaborado por los autores del manual que debe ser memorizado por los estudiantes. El método del historiador se obvia y los hechos del pasado se muestran de forma acrítica y como elementos objetivos. Esta práctica provoca una concepción epistémica errónea en el alumnado, que piensa en la ciencia histórica y en el pasado como realidades miméticas.

En los manuales franceses los resultados muestran un tratamiento más profundo de las competencias históricas, sobre todo relacionadas con las fuentes y pruebas, ejercicios de causas y consecuencias, y del cambio y la continuidad. El texto elaborado por los autores del manual es más reducido y el $80 \%$ de los ejercicios busca la interpretación de fuentes de diferente naturaleza (textual e icónica). Hay una gran presencia de fragmentos de textos de la época, combinados con textos de historiadores. Los ejercicios de los libros de texto exigen al alumnado el análisis de esas fuentes con preguntas de diferente dificultad: desde la localización de elementos históricos a la relación de conceptos o preguntas inferenciales. En consecuencia, las habilidades cognitivas son más complejas y el tratamiento de conceptos históricos de segundo orden más profundo. 
Sin embargo, la escasez de ejercicios que consoliden los conceptos de relevancia y de conciencia histórica en ambos países supone un hándicap negativo en la alfabetización del alumnado. Y esto está muy relacionado con la presentación de un discurso histórico demasiado lineal, que gira en torno a la construcción de la nación, muy estrechamente relacionada con la teoría de la modernización (Le Goff, 1988). Los manuales centran su atención en los protagonistas de esa modernidad: la burguesía, el comercio, las nuevas teorías políticas y la sociedad urbana. Es curioso que el campesinado, que suponía entre el 85-90 \% de la sociedad, no tenga ni una sola mención en los manuales franceses y apenas alguna alusión en los manuales españoles. Es cierto que en Francia los libros de texto proponen un mejor tratamiento de fuentes históricas y el desarrollo y evaluación de habilidades cognitivas sobre esta disciplina. Pero al igual que en el caso español no se discute la interpretación histórica derivada de la teoría de la modernización y siguen teniendo un peso excesivo las narrativas maestras de la construcción de la nación (Carretero, Asensio y Rodríguez-Moneo, 2011). Sin duda este es uno de los elementos clave a mejorar en los manuales: que el alumno reflexione sobre el discurso histórico oficial, dotándole de las herramientas teóricas y metodológicas adecuadas que le permitan interpretar de forma crítica el pasado.

\section{BIBLIOGRAFÍA}

ALRIDGE, D. P. (2006), "The Limits of Master Narratives in History Textbooks: An Analysis of Representations of Martin Luther King, Jr.", Teachers College Record, 108(4), 662686.

ÁlVAREZ JUNCO, J. (coord.) (2013), Las historias de España. Visiones del pasado y construcción de identidad, Madrid, Crítica-Marcial Pons.

AUDIGIER, F. y TUTIAUX-GUILLON, N. (2004), Regards sur l'histoire, la géographie et l'éducation civique à l'école primaire, Lyon, INRP.

BAQUĖS, M-C. (2007), "L'évolution des manuels d'histoire du lycée. Des années 1960 aux manuels actuels", Histoire de l'Education, 114, 121-149.

BARTON, K. C. (2008), "Research on Students. Ideas about History", en Levstik, L. y Tyson, C. (eds.), Handbook of Research in Social Studies Education, New York, Routledge.

(2010), "Historia e identidad. El reto de los investigadores pedagógicos", en Ávila, R. M., Rivero, P. y Domínguez, P. (eds.), Metodología de investigación en Didáctica de las Ciencias Sociales, Zaragoza, Diputación de Zaragoza, 13-28.

BARTON, K. y LEVSTIK, L. (2004), Teaching History for the Common Good, New Jersey, Lawrence Erlbau.

BORRIES, B., KÖRBER, A. y MEYER-HAMME, J. (2006), "Uso reflexive de los manuals escolares de historia: resultados de una encuesta realizada a docents, alumnus y universitarios", Enseñanza de las Ciencias Sociales. Revista de investigación, 5, 3-19.

BRAUDEL, F. (1968), La historia y las ciencias sociales, Madrid, Alianza.

CAJANI, L. (2006), "Italian History Textbooks on the Brink of the Twenty-first Century", en Nicholls, J. (ed.), School History Textbooks across Cultures: International Debates and Perspectives, Oxford, Symposium books, 27-41.

CARRETERO, M. (2006), Documentos de identidad. Contradicción y sentido de la enseñanza de la Historia, Barcelona, Paidós.

(2011), Constructing Patriotism. Teaching History and Memories in Global Worlds, Charlotte, Information Age Publishing.

CARRETERO, M. y otros (2013), "La construcción del conocimiento histórico", Propuesta Educativa, 39 (1), 13-23. 
CARRETERO, M. y LÓPEZ, C. (2010), "The Narrative Mediation on Historical Remembering", en Salvatore, S., Valsiner, J., Simon, J. T. y Gennaro, A. (eds.), Yearbook of Idiographic Science, vol. 3, Roma, Firera y Liuzzo, 285-294.

CARRETERO, M., LÓPEZ, C., GONZÁLEZ, M. F., y RODRÍGUEZ-MONEO, M. (2012), "Students Historical Narratives and Concepts about the Nation", en Carretero, M., Asensio, M. y Rodríguez-Moneo, M. (eds.), History Education and the Construction of National Identities, Charlotte, Information Age Publishing, 153-170.

CARRETERO, M., ROSA, A. y GONZÁLEZ, M. F. (2006), "Enseñar historia en tiempos de memoria", en Carretero, M., Rosa, A. y González, M. F. (comp.), La enseñanza de la historia y memoria colectiva, Buenos Aires, Editorial Paidós, 11-36.

CARRETERO, M., ASENSIO, M. y RODRÍGUEZ-MONEO, M. (2011) (eds.), History Education and the Construction of National Identities, Charlotte, IAP Publishing.

CARRETERO, M. y VAN ALPHEN, F. (2014), "Do Master Narratives Change Among High School Students? A Characterization of How National History Is Represented", Cognition and Instruction, 32:3, 290-312.

CHARTIER, C. (2007), La historia o la lectura del tiempo, Madrid, Gedisa.

DOMínGUEZ, J. (2015), Pensamiento histórico y evaluación de competencias, Barcelona, Graó.

ELMERSJÖ, H. A (2014), "History beyond Borders: Peace Education, History Textbooks Revision, and the Internationalization of History Teaching in the Twentieth Century", Historical Encounters. A Journal of Historical Consciousness, Historical Cultures and History Education, 1(1), 62-74.

FOSTER, S. (1999), "The Struggle for American Identity: Treatment of Ethnic Groups in United States History Textbooks", History of Education, 28, 251-279.

(2012), "Re-thinking History Textbooks in a Globalized World", en Carretero, M., Asensio, M. y Rodríguez-Moneo, M. (eds.), History Education and the Construction of National Identities, Charlotte, IAP Publishing, 49-62.

FOSTER, S. y CRAWFORD, K. A. (eds.) (2006), What shall We Tell the Children? International Perspectives on School History Textbooks, Greenwich, IAP.

GÓMEZ, C. J. (2014), "Pensamiento histórico y contenidos disciplinares en los libros de texto. Un análisis exploratorio de la Edad Moderna en $2^{\circ}$ de la ESO", Ensayos. Revista de la Facultad de Educación de Albacete, 29 (1),131-148.

GÓMEZ, C J., MIRALLES, P. y CÓZAR, R. (2014), "La enseñanza de la historia y el análisis de los libros de texto. Construcción de identidades y desarrollo de competencias", Ensayos. Revista de la Facultad de Educación de Albacete, 29 (1), 1-25.

GÓMEZ, C. J. y MIRALLES, P. (2015), “¿Pensar históricamente o memorizar el pasado? La evaluación de los contenidos históricos en la educación obligatoria en España", Revista de Estudios Sociales, 52, 52-68.

GÓMEZ, C. J. y MIRALLES, P. (2016), "Devéloppement et évaluation des compétences historiques dans les manuels scolaires. Une étude comparative France-Spagne", Spirale. Revue de Recherches en Éducation, 68, 55-66.

GÓMEZ, C. J., MOLINA PUCHE, S. y PAGÁN (2012), "Los manuales de Ciencias Sociales y la enseñanza de la Historia del Arte en $2^{\circ}$ de ESO", Ensayos. Revista de la Facultad de Educación de Albacete, 27, 69-88.

GÓMEZ, C. J., ORTUÑO, J. y MOLINAPUCHE, S. (2014), "Aprender a pensar históricamente. Retos para la historia en el siglo XXI", Tempo e Argumento, 6 (11), 5-27.

HEIMBERG, C. (2011), "L'enseignement de l'histoire dans un pays d'immigration: la Suisse", en López Facal, R. (edit.), Pensar históricamente en tiempos de globalización, Santiago de Compostela, USC publicacións, 21-35. 
HOBSBAWM, E. (1997), Nations and Nationalism since 1780: Program, Myth, Reality, Cambridge, Cambridge University Press.

KERLINGER, F. N. (2002), Investigación del comportamiento. Métodos de investigación en ciencias sociales, México, McGraw-Hill.

LE GOFF, J. (1988), Histoire et memoire, París, Gallimard.

LEE, P. (2005), "Putting Principles into Practice: Understanding History", en Donovan, M. y Bransford, J. (ed.), How students learn: History in the classroom, Whashington, National Academies Press, 31-77.

LÓPEZ FACAL, R. (2006), "Identidades posnacionales y enseñanza", Íber. Didáctica de las Ciencias Sociales, Geografía e Historia,47, 54-63.

(2009), "Sobre la enseñanza de la historia en los siglos XIX y XX", en Jannué, M. (ed.), Pensar històricament, Valencia, Universitat de València, 57-87.

(2010), "Nacionalismos y europeísmos en los libros de texto: identificación e identidad nacional", Clío y asociados, 14, 9-33.

(2013), "Competencias y enseñanza de las Ciencias Sociales", Íber. Didáctica de las Ciencias Sociales, Geografía e Historia, 74, 5-8.

(2014), "La LOMCE y la competencia histórica", Ayer, 94, 273-285.

MOLINA PUCHE, S. (2015), "Identidades colectivas y enseñanza de la historia en las sociedades multiculturales actuales", en Lima, L. y Pernas, P. (coord.), Didáctica de la historia. Problemas y métodos, México, El Dragón Rojo, 223-258.

MOLINA PUCHE, S., GÓMEZ, C. J. y ORTUÑO, J. (2014), "History Education under the New Educational Reform: New Wine in Old Bottles?", International Journal of Historical Learning, 12 (2), 122-132.

MOLINA PUCHE, S., MIRALLES, P. DEUSDAD, B. y ALFAGEME, M. B. (2016), “Enseñanza de la historia, creación de identidades y prácticas docentes", Profesorado, en prensa.

MOREAU, J. (2003), Schoolbook Nation: Conflicts over American History Textbooks from the Civil War to the Present, Ann Arbor, The University of Michigan Press.

NICHOLLS, J. (2003), "Methods in School Textbooks Research", International Journal of Historical Learning. Teaching and Research, 3 (1).

(2006), School History Textbooks across Cultures: International Debates and Perspectives, Oxford, Symposium Books.

NYGREN, T. (2011), History in the Service of Mankind: International Guidelines and History Education in Upper Secondary Schools in Sweden, 1927-2002, Umeå, Umeå University.

OGIER, A. (2007), "Le rôle du manuel dans la leçon d'histoire à l'école primaire (18701969)", Histoire de l'Education, 114, 87-119.

PÉREZ GARZÓN, J. S. (2008), “¿Por qué enseñamos geografía e historia? ¿Es tarea educativa la construcción de identidades?", Historia de la educación, 27, 37-55.

PERRENOUD, P. (2004), Diez nuevas competencias para aprender, Querétaro, Quebecor World.

PINGEL, F. (2000), The European Home: Representations of 20th Century Europe in History Textbooks, Strasbourg, Council of Europe.

PLÁ, S. (2012), "La enseñanza de la historia como objeto de investigación", Secuencia, 84, 163-184.

PRATS, J. (2010), "En defensa de la historia como materia educativa", Tejuelo. Didáctica de la Lengua y la Literatura, 9, 8-17.

RODRÍGUEZ LESTEGÁS, F. (2008), "La construcción de identidades, tarea atribuida a la escuela y al profesorado", Revista electrónica interuniversitaria del profesorado, 11(1), 1-8.

ROSA, A. (2004), "Memoria, historia e identidad. Una reflexión sobre el papel de la 
enseñanza de la historia en el desarrollo de la ciudadanía", en Carretero, M. y Voss, J. (comps.), Aprender y pensar la historia, Buenos Aires, Amorrortu, 47-70.

SÁIZ, J. (2010), “¿Qué historia medieval enseñar y aprender en Educación Secundaria?”, Imago Temporis. Medium Aevum, IV, 594-607.

(2013), "Alfabetización histórica y competencias básicas en libros de texto de historia y en aprendizaje de los estudiantes", Didáctica de las Ciencias Experimentales y Sociales, 27, 43-66.

SEIXAS, P. y MORTON, T. (2013), The Big Six Historical Thinking Concepts, Toronto, Nelson. STÖBER, G. (2013), "From Textbook Comparison to Common Textbooks? Changing Patterns in International Textbook Revision", en Korostelina, K. V. y Lässig, S. (eds.), History Education and Post-conflict Reconciliation: Reconsidering Joint Textbook Projects, New York, Routledge, 26-51.

THORNTON, S. J. (2006), "What is History in US History Textbooks?", en Nicholls, J. (ed.), School History Textbooks across Cultures: International Debates and Perspectives, Oxford, Symposium books, 15-25.

TOPOLSKY, J. (2004), "La estructura de las narrativas históricas y la enseñanza de la historia", en Carretero, M. y Voss, J. (comp.) (2004), Aprender y pensar la historia, Buenos Aires, Amorrortu, 101-120.

VALLS, R. (2001), "Los estudios sobre manuales escolares de historia y sus nuevas perspectivas", Didáctica de las Ciencias Experimentales y Sociales, 15, 23-36.

(2008), La enseñanza de la Historia y textos escolares, Buenos Aires, Zorzal.

VANSLEDRIGHT, B. A. (2011), The Challenge of Rethinking History Education. On Practice, Theories, and Policy, New York, Routledge.

(2014), Assessing Historical Thinking and Understanding. Innovation Design for New Standards, New York, Routledge.

VILAR, P. (1974), "Problèmes théoriques de I'histoire économique", en Vilar, P. (coord.), Aujord'hui l'histoire, París, Éditions Sociaux.

WERTSCH, J. V. (2002), Voices of Collective Remembering, Cambridge, Cambridge University Press.

WINEBURG, S. (2001), Historical Thinking and Other Unnatural Acts: Charting the Future of Teaching the Past, Philadelphia, Temple University Press. 


\section{ANEXOS}

Anexo 1. Tipología de contenidos y ejemplos en las actividades.

\begin{tabular}{|c|c|}
\hline TIPO DE CONTENIDO & EJEMPLO \\
\hline HISTORIA DEL ARTE Y CULTURAL & $\begin{array}{c}\text { ¿Qué papel jugó Roma en el } \\
\text { Cinquecento?¿Qué obra simboliza su } \\
\text { poder? }\end{array}$ \\
\hline HISTORIA POLITICA E & $\begin{array}{c}\text { ¿Cuándo se instauró en Inglaterra } \\
\text { una república? ¿Y una monarquía } \\
\text { parlamentaria? }\end{array}$ \\
\hline HISTORIA SOCIAL Y ECONÓMICA & $\begin{array}{c}\text { ¿Por qué las ciudades portuarias fueron } \\
\text { el centro de las nuevas actividades } \\
\text { capitalistas? }\end{array}$ \\
\hline
\end{tabular}

Anexo 2. Categorización de la tipología de actividades analizadas en los libros de texto.

\begin{tabular}{|c|c|c|}
\hline $\begin{array}{c}\text { TIPO } \\
\text { ACTIVIDAD }\end{array}$ & SIGNIFICADO & EJEMPLO \\
\hline $\begin{array}{l}\text { Búsqueda de } \\
\text { información }\end{array}$ & $\begin{array}{c}\text { Se pide al alumnado que busque } \\
\text { información sobre un personaje o } \\
\text { acontecimiento histórico en otras } \\
\text { fuentes. }\end{array}$ & $\begin{array}{l}\text { Busca más información sobre } \\
\text { la vida de Luis XIV y escribe un } \\
\text { resumen sobre su reinado. }\end{array}$ \\
\hline $\begin{array}{l}\text { Comentario } \\
\text { de texto }\end{array}$ & $\begin{array}{l}\text { Se pide al alumnado que } \\
\text { responda a una serie de preguntas } \\
\text { relacionadas con un texto histórico } \\
\text { de la época. }\end{array}$ & $\begin{array}{c}\text { ¿Quiénes eran los } \\
\text { Comuneros? ¿Qué demandas } \\
\text { le planteaban al rey en este } \\
\text { texto? }\end{array}$ \\
\hline Creación & $\begin{array}{c}\text { Se pide al alumnado que elabore } \\
\text { algún tipo de recurso relacionado } \\
\text { con contenidos históricos del } \\
\text { manual. }\end{array}$ & $\begin{array}{c}\text { Elige un asunto de la unidad } \\
\text { que te haya interesado. } \\
\text { Busca información sobre } \\
\text { él y confecciona un póster } \\
\text { explicativo. Después, exponlo } \\
\text { en el aula }\end{array}$ \\
\hline Ensayo & $\begin{array}{l}\text { Se pide al alumnado que realice un } \\
\text { ensayo sobre un tema o personaje } \\
\text { histórico. }\end{array}$ & $\begin{array}{l}\text { Escribe un ensayo sobre la } \\
\text { Guerra de los Treinta Años. }\end{array}$ \\
\hline $\begin{array}{l}\text { Figuras/ } \\
\text { imágenes }\end{array}$ & $\begin{array}{l}\text { Se pide al alumnado que responda } \\
\text { una serie de preguntas sobre } \\
\text { figuras, gráficos o imágenes. }\end{array}$ & $\begin{array}{l}\text { ¿Qué elementos típicos del } \\
\text { arte grecorromano distingues? } \\
\text { Explica el gráfico sobre las } \\
\text { exportaciones }\end{array}$ \\
\hline $\begin{array}{l}\text { Pregunta } \\
\text { corta }\end{array}$ & $\begin{array}{l}\text { Se pide al alumnado que responda } \\
\text { una pregunta corta sobre el texto } \\
\text { elaborado del manual (no sobre } \\
\text { textos históricos de la época). }\end{array}$ & $\begin{array}{c}\text { ¿Por qué las ciudades } \\
\text { portuarias fueron el centro } \\
\text { de las nuevas actividades } \\
\text { capitalistas? }\end{array}$ \\
\hline $\begin{array}{l}\text { Prueba } \\
\text { objetiva }\end{array}$ & $\begin{array}{l}\text { Se pide al alumnado un ejercicio } \\
\text { de corrección objetiva (unir flechas, } \\
\text { rellenar huecos, etc.). }\end{array}$ & $\begin{array}{c}\text { Copia en tu cuaderno y une } \\
\text { con flechas }\end{array}$ \\
\hline
\end{tabular}


Anexo 3. Significado y ejemplos del nivel cognitivo exigido al alumnado en las actividades de los libros de texto.

\begin{tabular}{|c|c|c|}
\hline $\begin{array}{c}\text { NIVEL } \\
\text { COGNITIVO }\end{array}$ & SIGNIFICADO & EJEMPLO \\
\hline 1 & $\begin{array}{l}\text { Implican la localización y } \\
\text { repetición de información presente } \\
\text { en recursos de enseñanza- } \\
\text { aprendizaje de la historia: textos } \\
\text { académicos, fuentes escritas } \\
\text { primarias o secundarias, gráficos, } \\
\text { mapas, ejes cronológicos o } \\
\text { imágenes. Son las que activan } \\
\text { conocimientos declarativos de } \\
\text { formulación literal o de base de } \\
\text { texto. Se trataría de saber, localizar } \\
\text { y extraer información literal de } \\
\text { un texto académico, una fuente } \\
\text { escrita, un mapa, un gráfico, un } \\
\text { eje o una imagen. Sólo suponen } \\
\text { destrezas de lectura, descripción, } \\
\text { localización, repetición, } \\
\text { reproducción y/o memorización } \\
\text { de información textual o icónica a } \\
\text { nivel básico. }\end{array}$ & $\begin{array}{l} \\
\text { ¿Qué guerra enfrentó } \\
\text { a los Borbones y a los } \\
\text { Habsburgo por el trono } \\
\text { español? } \\
\text { Copia estas frases en tu } \\
\text { cuaderno e indica si son } \\
\text { verdaderas o falsas (4): } \\
\text { Felipe III mandó construir } \\
\text { el palacio de Versalles. }\end{array}$ \\
\hline 2 & $\begin{array}{l}\text { Aquéllas que requieren } \\
\text { comprender la información } \\
\text { inserta en el recurso (texto } \\
\text { académico, fuente, mapa, } \\
\text { eje cronológico, imagen, etc.) } \\
\text { resumiéndola, parafraseándola } \\
\text { o esquematizándola; localizar la } \\
\text { idea principal del recurso, resumir } \\
\text { la información ofrecida en el } \\
\text { mismo y/o hacer un esquema } \\
\text { de ella, definir conceptos, } \\
\text { relacionar, establecer semejanzas } \\
\text { o diferencias entre ellos; buscar } \\
\text { y resumir nueva información en } \\
\text { otras fuentes; y finalmente el } \\
\text { confeccionar sencillos recursos } \\
\text { (construir ejes cronológicos, } \\
\text { sencillos mapas temáticos y } \\
\text { gráficos) a partir de información } \\
\text { básica. }\end{array}$ & $\begin{array}{l}\text { Resume las causas de la } \\
\text { crisis del siglo XVII y sus } \\
\text { consecuencias. } \\
\text { Identifica las actividades } \\
\text { comerciales. ¿A qué se } \\
\text { debían? } \\
\text { Comentario de texto. } \\
\text { ¿Qué medios militares } \\
\text { empleaban los } \\
\text { españoles? ¿Cuál era, } \\
\text { según Pizarro, el objetivo } \\
\text { de la conquista? }\end{array}$ \\
\hline
\end{tabular}




\begin{tabular}{|c|c|c|}
\hline $\begin{array}{c}\text { NIVEL } \\
\text { COGNITIVO }\end{array}$ & SIGNIFICADO & EJEMPLO \\
\hline 3 & $\begin{array}{l}\text { Aquéllas que exigen de los } \\
\text { alumnos analizar, aplicar, evaluar } \\
\text { información extraída de diferentes } \\
\text { recursos o las que implican la } \\
\text { creación de nueva información. } \\
\text { Parten del nivel anterior y derivan } \\
\text { de la resolución de preguntas } \\
\text { inferenciales y de la aplicación de } \\
\text { contenidos procedimentales como } \\
\text { estrategias. Ejercicios de empatía } \\
\text { histórica, simulaciones o estudios } \\
\text { de caso; la redacción de biografías } \\
\text { simuladas aplicando contenidos } \\
\text { declarativos aprendidos; la } \\
\text { valoración crítica o heurística } \\
\text { de información proporcionada } \\
\text { por las fuentes; el contrastar un } \\
\text { mismo fenómeno en dos fuentes o } \\
\text { diferentes interpretaciones sobre } \\
\text { un mismo hecho; confección de } \\
\text { informes, autoexplicaciones o } \\
\text { conclusiones obtenidas fruto del } \\
\text { análisis de diferentes recursos. }\end{array}$ & $\begin{array}{l} \\
\text { Reflexiona y contesta: } \\
\text { ¿por qué Magallanes } \\
\text { no exploró las costas de } \\
\text { Brasil? } \\
\text { Las imágenes inferiores } \\
\text { son de un microscopio } \\
\text { y un telescopio. Uno } \\
\text { se atribuye a Zacharias } \\
\text { Jansen y el otro fue } \\
\text { perfeccionado por Galileo } \\
\text { Galilei. Redacta un texto } \\
\text { de diez líneas explicando } \\
\text { por qué te parecen } \\
\text { importantes dichos } \\
\text { inventos }\end{array}$ \\
\hline
\end{tabular}


Anexo 4. Contenidos y criterios de evaluación sobre la Edad Moderna en $2^{\circ}$ y $4^{\circ}$ de la ESO según el decreto 291/2007 de la Región de Murcia.

\begin{tabular}{|c|c|}
\hline CONTENIDOS & CRITERIOS DE EVALUACIÓN \\
\hline $\begin{array}{l}\text { El Estado moderno en Europa. } \\
\text { El fortalecimiento del poder } \\
\text { real. Renacimiento y Reforma. } \\
\text { Humanismo y crisis religiosa. }\end{array}$ & $\begin{array}{l}\text { 9. Interpretar los cambios de } \\
\text { mentalidades que caracterizan la } \\
\text { modernidad y, en concreto, describir } \\
\text { los rasgos básicos del Renacimiento } \\
\text { y de la Reforma. } \\
\text { 10. Distinguir los principales } \\
\text { momentos en la formación y } \\
\text { evolución del Estado moderno y } \\
\text { destacar los hechos más relevantes } \\
\text { de la Monarquía Hispánica. }\end{array}$ \\
\hline $\begin{array}{l}\text { Evolución política y económica en } \\
\text { España. La monarquía de los Reyes } \\
\text { Católicos. La expansión europea: las } \\
\text { Islas Canarias. El descubrimiento de } \\
\text { América y su impacto económico. }\end{array}$ & $\begin{array}{l}\text { 11. Valorar la importancia de la } \\
\text { ampliación del mundo conocido y } \\
\text { subrayar el protagonismo de Castilla } \\
\text { y Portugal en la gesta americana. } \\
\text { 12. Conocer las características } \\
\text { generales de la monarquía española } \\
\text { de los siglos XVI y XVII e incidir en } \\
\text { la organización territorial hispánica y } \\
\text { del Imperio. }\end{array}$ \\
\hline $\begin{array}{l}\text { La España del siglo XVI. La Europa } \\
\text { de Carlos V. La Monarquía Hispánica } \\
\text { de Felipe II. Arte y cultura en el siglo } \\
\text { XVI }\end{array}$ & $\begin{array}{l}\text { 12. Conocer las características } \\
\text { generales de la monarquía española } \\
\text { de los siglos XVI y XVII e incidir en } \\
\text { la organización territorial hispánica y } \\
\text { del Imperio. } \\
\text { 13. Analizar el arte del Renacimiento } \\
\text { y del Barroco y aplicar este } \\
\text { conocimiento al análisis de algunas } \\
\text { obras y autores representativos. } \\
\text { 14. Conocer las principales } \\
\text { manifestaciones artísticas } \\
\text { y culturales para valorar su } \\
\text { significación como patrimonio } \\
\text { histórico, con especial referencia } \\
\text { y valoración del patrimonio de la } \\
\text { Región de Murcia }\end{array}$ \\
\hline
\end{tabular}


La lucha por la hegemonía y el relevo del poder político: La Europa del Barroco. Transformaciones políticas y económicas. La Europa de Westfalia. La crisis de la monarquía de los Austrias. El Siglo de Oro: arte y cultura.
12. Conocer las características generales de la monarquía española de los siglos XVI y XVII e incidir en la organización territorial hispánica y del Imperio.

13. Analizar el arte del Renacimiento y del Barroco y aplicar este conocimiento al análisis de algunas obras y autores representativos 14. Conocer las principales manifestaciones artísticas y culturales para valorar su significación como patrimonio histórico, con especial referencia y valoración del patrimonio de la Región de Murcia

La expansión americana: organización territorial, transformaciones económicas y sociales. Arte y cultura en la América hispana.

El Estado absoluto. Despotismo ilustrado y parlamentarismo inglés. La llustración. Reformismo borbónico en España y América. El Reino de Murcia en el siglo XVIII: Belluga y Floridablanca. El arte del siglo XVIII: el Barroco y el Neoclasicismo. Salzillo. La Catedral de Murcia. Otras manifestaciones del Barroco en la Región de Murcia.

Transformaciones políticas y económicas en la Europa del Antiguo Régimen. La independencia de EEUU. La Revolución Francesa.
11. Valorar la importancia de la ampliación del mundo conocido y subrayar el protagonismo de Castilla y Portugal en la gesta americana.

1. Analizar las transformaciones del siglo XVIII, especialmente las del reformismo borbónico en España y América.

2. Conocer, a través de sus principales protagonistas, los acontecimientos políticos y artísticos del siglo XVIII en la Región de Murcia.

3. Distinguir los cambios políticos que conducen a la crisis del Antiguo Régimen y a las revoluciones liberales, así como su repercusión en España. 
Anexo 5. Contenidos y capacidades sobre la Edad Moderna en el Programme du Collége de 2008 $\left(4^{\circ}\right.$ y $\left.5^{\circ}\right)$

\begin{tabular}{|c|c|}
\hline CONTENIDOS & CAPACIDADES \\
\hline $\begin{array}{l}\text { LES BOULEVERSEMENTS CULTURELS } \\
\text { ET INTELLECTUELS (XVe-XVIIe siècle) } \\
\text { Entre le XVe et le XVIle siècle, l'Europe } \\
\text { connaît des bouleversements culturels, } \\
\text { religieux et scientifiques qui donnent une } \\
\text { nouvelle vision du monde et de l'homme. } \\
\text { - Les découvertes européennes et la } \\
\text { conquête et des empires ouvrent le } \\
\text { monde aux Européens. } \\
\text { - La Renaissance renouvelle les formes } \\
\text { de l'expression artistique. } \\
\text { - La crise religieuse remet en cause } \\
\text { l'unité du christianisme. } \\
\text { occidental (Réformes) au sein duquel } \\
\text { les confessions s'affirment et s'affrontent } \\
\text { (catholiques, protestants). } \\
\text { - La révolution de la pensée scientifique } \\
\text { aux XVle et XVIle siècles introduit une } \\
\text { nouvelle conception du monde. }\end{array}$ & $\begin{array}{l}\text { Connaître et utiliser les repères suivants: } \\
\text { 1. Le premier voyage de Christophe } \\
\text { Colomb (1492) ou le voyage de Magellan } \\
\text { (1519 -1521) sur une carte du monde. } \\
\text { 2. La Renaissance (Xve-XVle siècle) et } \\
\text { ses foyers en Europe. } \\
\text { 3. Le siècle des Réformes et des guerres } \\
\text { de religion: XVle siècle. } \\
\text { Raconter et expliquer un épisode des } \\
\text { découvertes ou de la conquête de } \\
\text { l'empire espagnol d'Amérique. } \\
\text { Raconter un épisode de la vie d'un artiste } \\
\text { ou d'un mécène ou décrire un monument } \\
\text { ou une oeuvre d'art comme témoignages } \\
\text { de la Renaissance. } \\
\text { Raconter un épisode significatif des } \\
\text { Réformes (dans les vies de Luther, de } \\
\text { Calvin ou d'un réformateur catholique...) } \\
\text { et expliquer ses conséquences. } \\
\text { Raconter un épisode significatif des } \\
\text { progrès ou débats scientifiques des XVle } \\
\text { et XVIle siècles (Copernic ou Galilée...) et } \\
\text { expliquer sa nouveauté. }\end{array}$ \\
\hline $\begin{array}{l}\text { L'ÉMERGENCE DU "ROI ABSOLU" } \\
\text { La monarchie française subit une éclipse } \\
\text { dans le contexte des conflits religieux du } \\
\text { XVle siècle, à l'issue desquels l'État royal } \\
\text { finit par s'affirmer comme seul capable } \\
\text { d'imposer la paix civile (1598). } \\
\text { Les rois revendiquent alors un "pouvoir } \\
\text { absolu" qui atteint son apogée avec Louis } \\
\text { XIV et se met en scène à Versailles. }\end{array}$ & $\begin{array}{l}\text { Connaître et utiliser les repères suivants: } \\
\text { 1. L'Édit de Nantes, } 1598 . \\
\text { 2. L'évolution des limites du royaume, du } \\
\text { début du XVle siècle à } 1715 \text {. } \\
\text { 3. 1661-1715: le règne personnel de } \\
\text { Louis XIV: } \\
\text { Raconter une journée de Louis XIV à } \\
\text { Versailles révélatrice du pouvoir du roi. }\end{array}$ \\
\hline
\end{tabular}




\section{L'EUROPE DES LUMIÈRES}

Connaître et utiliser les repères suivants

Au XVIIle siècle, les philosophes et les savants mettent en cause les fondements religieux, politiques, économiques et sociaux de la société d'ordres.

- Les grandes puissances politiques en Europe sur une carte de l'Europe au début du XVIIIe siècle.

- Leurs empires coloniaux sur une carte du monde au début du XVIIle siècle.

- Quelques grandes routes maritimes.

\section{L'EUROPE DANS LE MONDE AU}

DÉBUT DU XVIIIe SIÈCLE

Les grandes puissances européennes

et leurs domaines coloniaux, les grands courants d'échanges mondiaux au début du XVIIIe siècle.

\section{LES TRAITES NÉGRIÈRES ET}

L'ESCLAVAGE

La traite est un phénomène ancien

en Afrique. Au XVIIIe siècle, la traite atlantique connaît un grand développement dans le cadre du "commerce triangulaire" et de l'économie de plantation.

\section{LES DIFFICULTÉS DE LA MONARCHIE} SOUS LOUIS XVI

Trois aspects sont retenus: les aspirations à des réformes politiques et sociales, l'impact politique de l'indépendance américaine, l'impossible réforme financière.

\section{LES TEMPS FORTS DE LA}

\section{RÉVOLUTION}

L'accent est mis sur trois moments:

\section{-1789-1791: l'affirmation de la}

souveraineté populaire, de l'égalité

juridique et des libertés individuelles.

-1792-1794: la République, la guerre et la

Terreur.

-1799-1804: du Consulat à l'Empire.
Connaître et utiliser le repère suivant:

1. L'Encyclopédie, milieu du XVIIle siècle.

Raconter quelques épisodes de la vie du philosophe ou du savant étudié, et expliquer en quoi ils sont révélateurs du siècle des Lumières.
Raconter la capture, le trajet, et le travail forcé d'un groupe d'esclaves.
Connaître et utiliser les repères suivants:

2. Le règne de Louis XVI: 1774-1792.

3. La Révolution américaine: 1776-1783.

Décrire et expliquer les principales difficultés de la monarchie française à la veille de la Révolution et quelques unes des aspirations contenues dans les cahiers de doléances.

Connaître et utiliser les repères suivants:

1. La Révolution française : 1789-1799.

Prise de la Bastille: 14 juillet 1789;

Déclaration des droits de l'homme et du citoyen: août 1789; proclamation de la République: septembre 1792.

2. Le Consulat et l'Empire: 1799-1815. Napoléon ler, empereur des Français: 1804.

Raconter quelques uns des événements retenus et expliquer leur importance. 